\title{
Continuous Flow Removal of Anionic Dyes in Water by Chitosan-Functionalized Iron Oxide Nanoparticles Incorporated in a Dextran Gel Column
}

\author{
Sang Yeob Lee ${ }^{1(\mathbb{D}, \text { Ha Eun Shim }}{ }^{2}$, Jung Eun Yang ${ }^{3}$, Yong Jun Choi ${ }^{4}\left(\mathbb{D}\right.$ and Jongho Jeon ${ }^{1, *(\mathbb{D}}$ \\ 1 Department of Applied Chemistry, School of Applied Chemical Engineering, Kyungpook National \\ University, Daegu 41566, Korea \\ 2 Department of Chemistry, Kyungpook National University, Daegu 41566, Korea \\ 3 Department of Advanced Process Technology and Fermentation, World Institute of Kimchi, \\ Gwangju 61755, Korea \\ 4 School of Environmental Engineering, University of Seoul, Seoul 02504, Korea \\ * Correspondence: jeonj@knu.ac.kr
}

Received: 19 July 2019; Accepted: 10 August 2019; Published: 14 August 2019

\begin{abstract}
This paper describes a novel chromatographic method for efficient removal of anionic dyes from aqueous solutions. Chitosan-coated $\mathrm{Fe}_{3} \mathrm{O}_{4}$ nanoparticles can easily be immobilized on a dextran gel column. Single elution of Evans Blue (EB) solution to the nanoadsorbent-incorporated columns provides high removal efficiency with a maximum adsorption capacity of $243.9 \mathrm{mg} / \mathrm{g}$. We also investigated the influence of initial concentration and solution $\mathrm{pH}$ on the removal efficiency of EB. The electrostatic interaction between the adsorbent surface and negatively charged sulfate groups on EB molecules promotes the efficient adsorption of dyes. The equilibrium data matched well with the Langmuir isotherm model, which indicated monolayer dye adsorption onto the adsorbent surface. To extend the application of the current method, we performed further adsorption experiments using other anionic dyes of different colors (Cy5.5, Acid Yellow 25, Acid Green 25, and Acid Red 1). All of these molecules can efficiently be captured under continuous flow conditions, with higher removal efficiency obtained with more negatively charged dyes. These findings clearly demonstrate that the present approach is a useful method for the removal of anionic dye contaminants in aqueous media by adsorption.
\end{abstract}

Keywords: iron oxide nanomaterials; anionic dye; purification; immobilization; nanocomposite; remediation; chromatography

\section{Introduction}

With the rapid development of various industries and the growth of manufacturing, the coinciding increase in pollution as a threat to the environment and public health has prompted considerable attention to improve the treatment of wastewater [1,2]. Among a variety of contaminants released into the environment, organic dyes are considered to be one of the most dangerous pollutants; many of these molecules are known to be toxic, mutagenic, and carcinogenic, which can have adverse effects on aquatic creatures and human beings [3-7]. Anionic dyes are particularly troublesome due to their high solubility in water, various harmful effects on living organisms, and large quantities generated from many industrial sources [8,9]. Moreover, these molecules are typically difficult to degrade due to their complex aromatic structures, and thus anionic dyes can persist as contaminants in water for long periods of time. Therefore, various physicochemical and biological processes for dye removal from wastewater have been investigated to solve this urgent environmental issue. Previously reported techniques for alleviation of dye-containing wastewater include adsorption [10-12], filtration [13], 
biodegradation [14], chemical coagulation [15], photocatalysis [16], and electrolysis [17], among other methods. The adsorption technique is regarded as the preferred separation method, and is therefore widely applied to remove organic dyes in aqueous media due to simplicity of design, high efficiency, low cost, and facile and controllable operation. Among various adsorbents, much attention has been paid to the use of metal oxide nanomaterials [18]. In recent years, adsorbents based on $\mathrm{Fe}_{3} \mathrm{O}_{4}$ nanomaterials have been widely investigated for efficient removal of dyes in wastewater due to their low toxicity, easy and inexpensive preparation, and large surface area. To date, most adsorption experiments using $\mathrm{Fe}_{3} \mathrm{O}_{4}$ have been performed using batch processing [19-22]. The adsorbents are immersed in the wastewater and then additional separation processes are required to remove the dye-adsorbed nanomaterials from the water after adsorption via an external magnetic field.

We previously studied and reported adsorbent-immobilized composite materials to perform continuous flow desalination of radioactive elements in water [23-26]. These hybrid nanomaterials stabilize the adsorbent and minimize aggregation/agglomeration of the adsorbent during water treatment. Moreover, these techniques allow easier separation of solid adsorbents from the decontaminated water. Our methods provided superior performance, such as rapid and high removal efficiency when compared to known batch processes. Herein, we report a convenient continuous flow process for efficient capture of anionic dyes using $\mathrm{Fe}_{3} \mathrm{O}_{4}$-incorporated dextran gel column. For this study, we have selected chitosan functionalized $\mathrm{Fe}_{3} \mathrm{O}_{4}$ nanoparticles because the cationic nature of chitosan can be helpful for the removal of anionic dyes from aqueous solutions and is also useful for stable immobilization of the nanoadsorbent in the dextran gel beads. Our current method employs affinity chromatography to remove dye contaminants in water, making use of the fact that chitosan-functionalized $\mathrm{Fe}_{3} \mathrm{O}_{4}$ adsorbents on solid supports are known to capture anionic dyes. First, the adsorption performance of the current system is evaluated systemically using Evans Blue (EB) dye and then the same method is further extended to the removal of several other anionic dyes.

\section{Materials and Methods}

\subsection{Materials}

Evans Blue, Acid Red 1, Acid Yellow 25, Acid Green 25, Amberlite ${ }^{\circledR}-410$, Amberlite ${ }^{\circledR}-900$, humic acid (HA), and $\mathrm{NaOH}$ were purchased from Sigma-Aldrich (Yongin, Korea). The dye Cyanine 5.5 (Cy5.5) and dextran gel desalting column (PD-10) were supplied by GE Healthcare. Chitosan-coated $\mathrm{Fe}_{3} \mathrm{O}_{4}$ nanomaterials and dextran sulfate-coated $\mathrm{Fe}_{3} \mathrm{O}_{4}$ nanomaterials were purchased from Chemicell (Berlin, Germany). All reagents were of analytical grade and used without further purification. Concentrations of dye solutions were measured using a UV-vis spectrophotometer (Shimadzu, UV-1800, Kyoto, Japan).

\subsection{Preparation of Chitosan- $\mathrm{Fe}_{3} \mathrm{O}_{4}$-Incorporated Desalting Column ( $\mathrm{Fe}-\mathrm{DC}$ )}

A dextran gel desalting column (PD-10) was washed with deionized water $(3 \times 5 \mathrm{~mL})$ and slowly loaded with a suspension of chitosan-coated $\mathrm{Fe}_{3} \mathrm{O}_{4}$ nanoparticles $(2.5 \mathrm{mg})$ in $10 \mathrm{~mL}$ deionized water. After the nanoparticles were incorporated in the cross-linked dextran gels, the column was further washed with pure water to provide Fe-DC. Preparation of Fe-DC could normally be accomplished in $20 \mathrm{~min}$.

\subsection{Characterization of Adsorbent}

The structure of chitosan- $\mathrm{Fe}_{3} \mathrm{O}_{4}$-incorporated dextran gel microbeads was observed using field emission scanning electron microscopy (SEM; FEI Verios 460L, Hillsboro, OR, USA) under high-performance conditions with accelerating voltages up to $15 \mathrm{kV}$. The elemental composition of the microbeads was analyzed by SEM-energy dispersive X-ray spectroscopy (EDX, AMITEC) analysis with accelerating voltages of up to $20 \mathrm{kV}$. EDX spectra were recorded in the area scan mode by focusing the electron beam onto a region of the sample surface. 


\subsection{Removal of Anionic Dyes in Water Using Fe-DC}

To measure the adsorption capacity of Fe-DC for Evans Blue (EB), an aqueous solution (75 mL) containing 2.5 to $100 \mu \mathrm{M}$ EB was poured into to Fe-DC and the flow rate was maintained at $\sim 1.5 \mathrm{~mL} / \mathrm{min}$. The eluate was collected every $3 \mathrm{~mL}(\times 25)$, and the concentration of each eluate was analyzed by UV-vis absorbance spectroscopy. The adsorption isotherm was analyzed by Langmuir, Freundlich, and Temkin equations as follows.

$$
\begin{gathered}
\text { Langmuir equation: } \frac{C_{e}}{q_{e}}=\frac{C_{e}}{q_{m}}+\frac{1}{q_{m} \mathrm{~K}_{\mathrm{L}}} \\
\text { Freundlich equation : } \operatorname{In} q_{e}=\operatorname{InK}_{\mathrm{F}}+\frac{1}{n} \ln C_{e} \\
\text { Temkin equation : } q_{e}=\mathrm{BInA}_{t}+\mathrm{BInC}_{e}
\end{gathered}
$$

where $C_{0}$ and $C_{\mathrm{e}}(\mu \mathrm{mol})$ are the initial concentration of the dye solution and the residual concentration in the eluate, respectively; $q_{\mathrm{e}}(\mathrm{mg} / \mathrm{g})$ is the amount of dye absorbed per unit mass of absorbent; and $q_{\mathrm{m}}$ $(\mathrm{mg} / \mathrm{g})$ is the maximum adsorption capacity of the adsorbent. $\mathrm{K}_{\mathrm{L}}$ and $\mathrm{K}_{\mathrm{F}}$ are the Langmuir adsorption constant and Freundlich constant, respectively. B is the constant related to the heat of sorption $(\mathrm{J} / \mathrm{mol})$ at $298 \mathrm{~K}$ and $\mathrm{A}_{t}$ is the Temkin isotherm equilibrium binding constant $(\mathrm{L} / \mathrm{g})$.

To evaluate removal efficiency of Fe-DC for anionic dye molecules, each solution $(10 \mathrm{~mL})$ was added to Fe-DC with $\sim 1.5 \mathrm{~mL} / \mathrm{min}$ flow rate. The removal efficiency (\%) is defined by the following equation to assess the adsorption capability of Fe-DC towards anionic dyes.

$$
\text { Removal efficiency }(\%)=\frac{C_{0}-C_{e}}{C_{0}} \times 100
$$

\section{Results and Discussion}

\subsection{Preparation of Chitosan- $\mathrm{Fe}_{3} \mathrm{O}_{4}$-Incorporated Desalting Column (Fe-DC)}

The key strategy of this study is illustrated in Figure 1a, whereby the column needs to be prepared before the capture of dye molecules can be performed. The first step is the preparation of the chitosan- $\mathrm{Fe}_{3} \mathrm{O}_{4}$-incorporated desalting column (Fe-DC). To immobilize the adsorbents, chitosan-coated iron oxide nanoparticles (chitosan- $\mathrm{Fe}_{3} \mathrm{O}_{4}$ ) were added to a commercially available PD-10 desalting column ( $8.3 \mathrm{~mL}$ bed volume). A chitosan- $\mathrm{Fe}_{3} \mathrm{O}_{4}(65 \mathrm{~nm}$ average hydrodynamic radius) (Figures $\mathrm{S} 1$ and S2) suspension $(10 \mathrm{~mL}$ ) was slowly added to the column (Figure S3). The positively charged chitosan $-\mathrm{Fe}_{3} \mathrm{O}_{4}$ nanoparticles (zeta potential $=+21.2$ at neutral $\mathrm{pH}$ ) became incorporated by interactions on the surface of negatively charged cross-linked dextran gels.

After chitosan- $\mathrm{Fe}_{3} \mathrm{O}_{4}$ nanoparticles enter the packed bed completely, the resulting column was washed with pure water to provide a chitosan- $\mathrm{Fe}_{3} \mathrm{O}_{4}$-incorporated desalting column (Fe-DC) (Figure $1 \mathrm{~b}$ ). The chitosan- $\mathrm{Fe}_{3} \mathrm{O}_{4}$ nanoparticles incorporated in the desalting column were stable and remain attached, as they do not elute nor undergo aggregation upon continual washing with water or aqueous solutions of $0.1 \mathrm{M} \mathrm{NaCl}$ or $0.1 \mathrm{M} \mathrm{NaOH}$. Under acidic conditions, however, both chitosan- $\mathrm{Fe}_{3} \mathrm{O}_{4}$ and the dextran gel are positively charged. Thus, some chitosan- $\mathrm{Fe}_{3} \mathrm{O}_{4}$ nanoparticles begin to elute from the column when the $\mathrm{pH}$ of eluent is strongly acidic $(\mathrm{pH}<3)$. To further investigate whether the incorporation of the adsorbent is caused by the electrostatic interaction between chitosan- $\mathrm{Fe}_{3} \mathrm{O}_{4}$ nanoparticles and the dextran gel beads, negatively charged dextran sulfate-coated $\mathrm{Fe}_{3} \mathrm{O}_{4}$ nanoparticles were added at neutral $\mathrm{pH}$. As expected, the nanoparticles were not immobilized by the dextran gels and were quickly eluted from the PD-10 column. These observations indicate that an electrostatic interaction between two oppositely charged components, namely positively charged chitosan- $\mathrm{Fe}_{3} \mathrm{O}_{4}$ nanoparticles and negatively charged dextran gel, lead to immobilization when $\mathrm{pH} \geq 4$. A series of magnified SEM images of Fe-DC (Figure 2 and Figure S4) indicate incorporation of chitosan- $\mathrm{Fe}_{3} \mathrm{O}_{4}$ on the surface of 
the dextran microbeads. In addition, elemental analysis using EDX exhibits peaks for iron from the nanoparticles, and carbon and oxygen from dextran (Figure 2f), clearly demonstrating incorporation of the chitosan- $\mathrm{Fe}_{3} \mathrm{O}_{4}$ nanoparticles as adsorbents on the PD-10 dextran gel desalting column.

a)

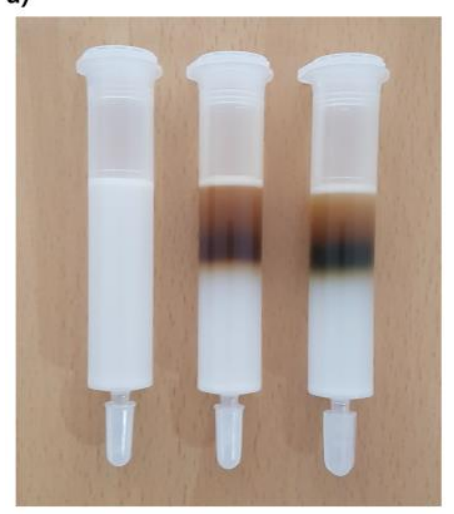

b)

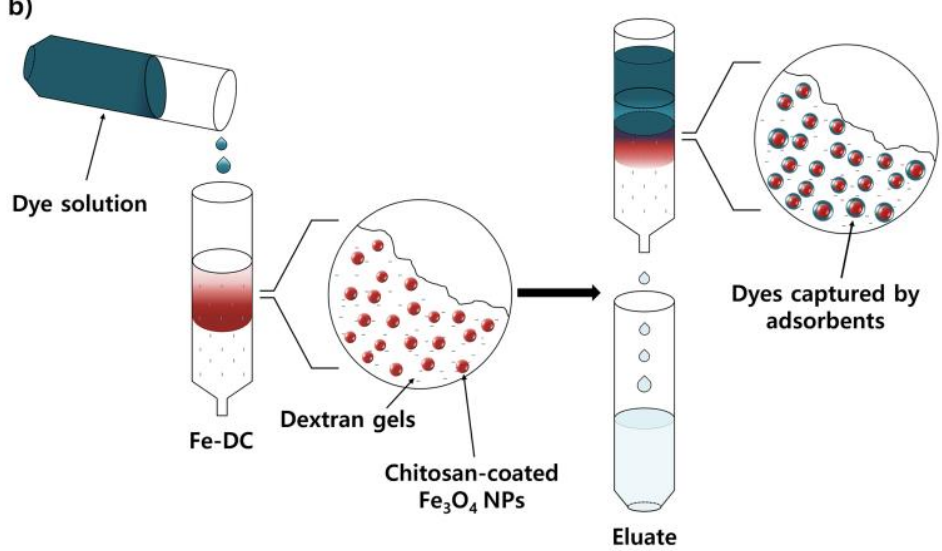

Figure 1. (a) Image of desalting columns: (left) bare PD-10, (middle) Fe-DC, and (right) Fe-DC after adsorption of EB; (b) schematic illustration of the dye adsorption process from aqueous solutions using Fe-DC under continuous flow conditions $(\sim 1.5 \mathrm{~mL} / \mathrm{min})$.
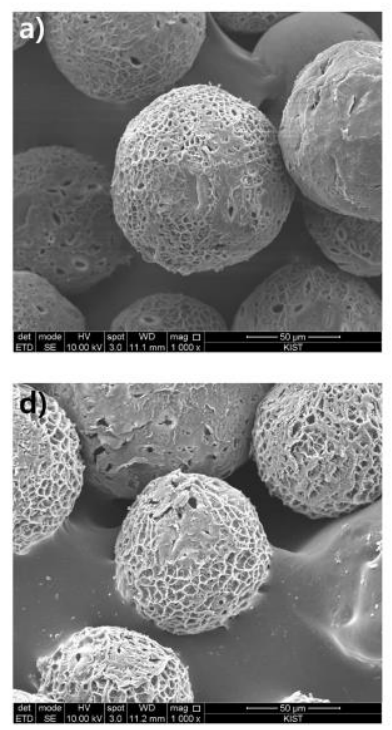
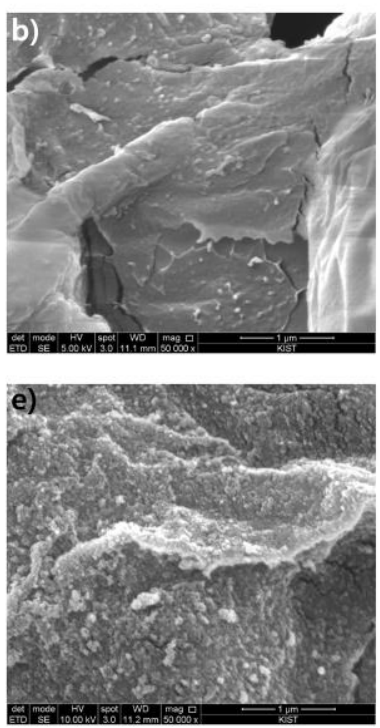
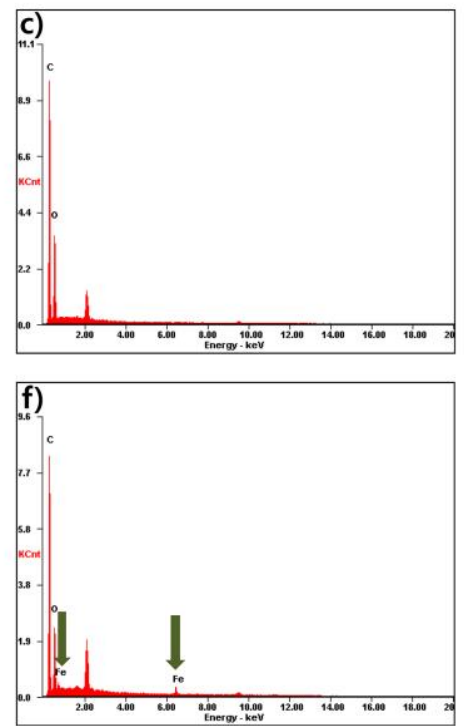

Figure 2. SEM images of $(\mathbf{a}, \mathbf{b})$ dextran gel and $(\mathbf{d}, \mathbf{e})$ chitosan- $\mathrm{Fe}_{3} \mathrm{O}_{4}$-incorporated dextran gel. EDX analysis of (c) dextran gel and (f) chitosan- $\mathrm{Fe}_{3} \mathrm{O}_{4}$-incorporated dextran gel; arrows indicate the presence of iron.

\subsection{Adsorption of Evans Blue (EB) Dye Using Fe-DC}

To initially investigate the removal efficiency of an anionic dye from an aqueous solution under continuous flow conditions, an aqueous solution of EB $(2.5 \mu \mathrm{M}, 75 \mathrm{~mL})$ was added to Fe-DC (Figure $1 \mathrm{~b}$ and Figure S5) at a rate of $1.5 \mathrm{~mL} / \mathrm{min}$. The concentration of dye in the eluate can be measured with UV-vis absorbance spectroscopy and the removal capability determined by dividing the concentration of the eluate by the initial concentration of the dye $\left(C / C_{0}\right)$. Figure 3a shows that EB is efficiently captured by Fe-DC, with $>99 \%$ removal efficiency maintained until $30 \mathrm{~mL}$ of the dye solution is passed through the Fe-DC. As shown in Figure 1a (right), EB is captured on Fe-DC after elution is complete. Dextran gel alone (PD-10 without incorporated chitosan- $\mathrm{Fe}_{3} \mathrm{O}_{4}$ nanoparticles) retains only a small fraction of EB non-specifically, with most of the dye molecules eluted almost immediately (Figure 3a), 
demonstrating that the removal of $\mathrm{EB}$ was mediated by chitosan- $\mathrm{Fe}_{3} \mathrm{O}_{4}$ nanoparticles incorporated in the column.
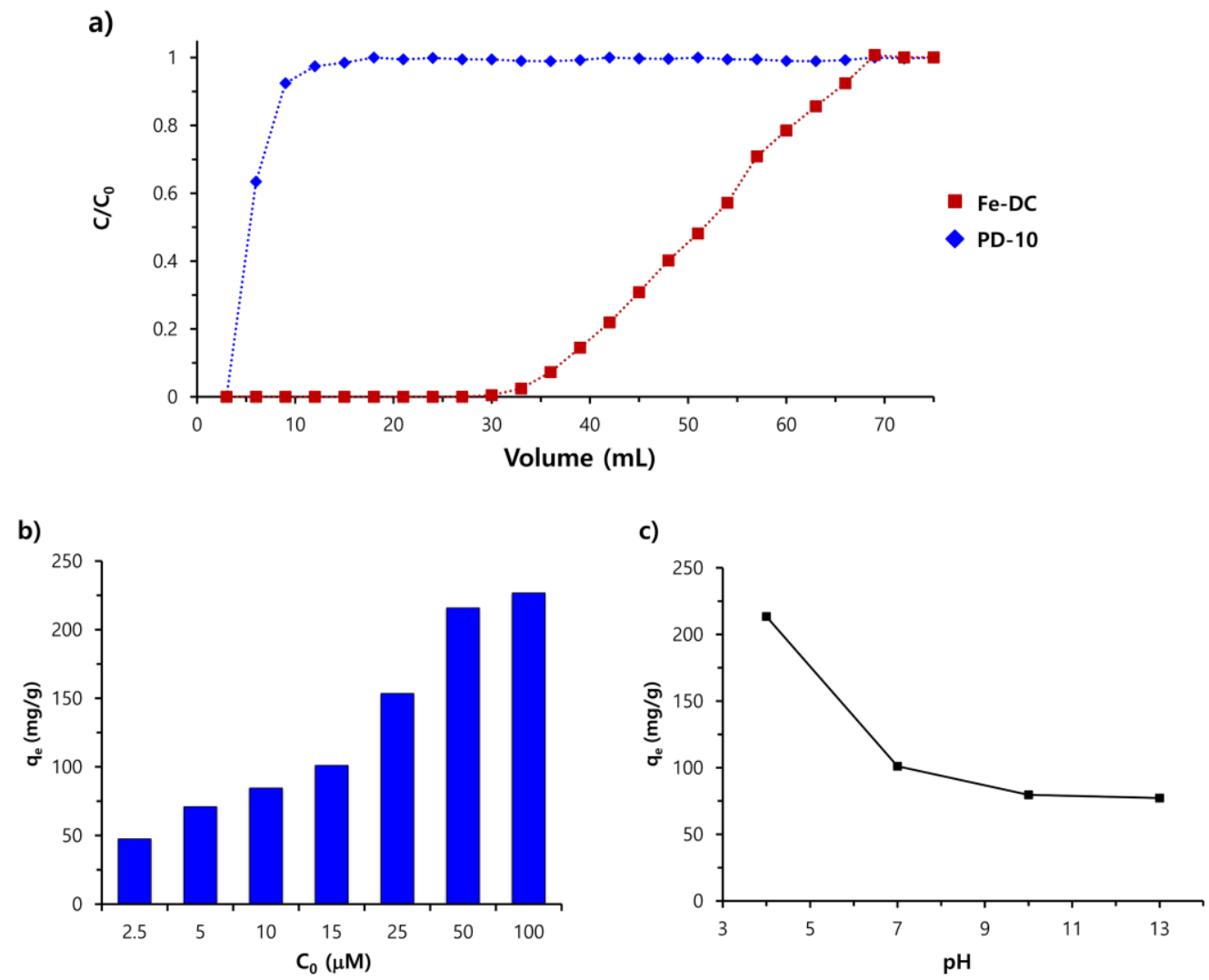

Figure 3. (a) Breakthrough curve for EB adsorption as a function of time using the Fe-DC column (where $C_{0}$ is $2.5 \mu \mathrm{M}$ of dye and $C$ is the measured concentration in the eluent) and bare PD-10, (b) effect of initial dye concentration on the adsorption efficiency, (c) effect of the initial solution $\mathrm{pH}$ on the adsorption efficiency of the Fe-DC column.

\subsection{Adsorption Isotherm Modeling}

After confirming that the incorporation of chitosan- $\mathrm{Fe}_{3} \mathrm{O}_{4}$ nanoparticles is indeed necessary for immobilization of EB, the adsorption efficiency and effect of $\mathrm{pH}$ were studied. Adsorption efficiency was studied using various concentrations of EB ranging from 2.5 to $100 \mu \mathrm{M}$. The adsorption capacity $\left(q_{\mathrm{e}}\right)$ of Fe-DC increases with the increasing initial concentration of EB (Figure 3b). The pH of the solution may also affect the adsorption performance by changing the surface properties of chitosan- $\mathrm{Fe}_{3} \mathrm{O}_{4}$ nanoparticles. To investigate the effect of solution $\mathrm{pH}$, aqueous solutions of EB (15 $\mu \mathrm{M})$ at $\mathrm{pH} 4,7$, 10 , and 13 were added to the Fe-DC. As shown in Figure $3 c$, the $q_{\mathrm{e}}$ tends to increase with decreasing $\mathrm{pH}$ (down to $\mathrm{pH} 4$ ), which indicates that EB can be adsorbed more easily under slightly acidic conditions rather than in alkaline media. This phenomenon can be attributed to the fact that as the $\mathrm{pH}$ decreases, chitosan- $\mathrm{Fe}_{3} \mathrm{O}_{4}$ becomes protonated (i.e., the amine group of chitosan), and thus the overall surface charge will become more positive, which results in enhanced adsorption efficiency by the stronger electrostatic attraction between the cationic ammonium groups on chitosan- $\mathrm{Fe}_{3} \mathrm{O}_{4}$ and anionic sulfate groups on EB [27]. At a higher $\mathrm{pH}$, more hydroxyl ions $\left(\mathrm{OH}^{-}\right)$in the aqueous media compete with negatively charged dyes, thus leading to less overall removal efficiency of EB. These mechanistic considerations explain how better adsorption capacity was obtained at a lower $\mathrm{pH}$. To further investigate the effects of other contaminants on adsorption capacity, we prepared a $15 \mu \mathrm{M}$ EB solution containing humic acid (HA), a heterogeneous macromolecule mainly found in soil and water. The solution was poured into Fe-DC under the abovementioned conditions. As shown in Figure S6, when the amount of HA was twice as much as that of EB, the observed qe equaled $70.8 \mathrm{mg} / \mathrm{g}$, 
which is $\sim 30 \%$ less than the value obtained for pure water $(101.08 \mathrm{mg} / \mathrm{g})$. This finding was ascribed to the fact that $\mathrm{HA}$ functional groups (e.g., catechol units) can also bind to the surface of $\mathrm{Fe}_{3} \mathrm{O}_{4}$ to occupy adsorption sites, which results in reduced adsorption ability.

To describe the adsorption isotherm of EB, the adsorption data are analyzed using three isothermal equations (Langmuir, Freundlich, and Temkin models) as described in Section 2.4. The linear fittings of the graphs with Equations (1)-(3) are shown in Figure 4, and the corresponding adsorption parameters for these models are summarized in Table 1. According to the calculated values, the Langmuir model matches more closely than the other two models, as it provides a higher correlation coefficient value $\left(R^{2}=0.9832\right)$. This result suggests that the adsorption of EB by the Fe-DC is monolayer adsorption [28]. The obtained maximum adsorption capacity $\left(q_{\max }\right)$ for EB is found to be $243.902 \mathrm{mg} / \mathrm{g}$ of the adsorbent.
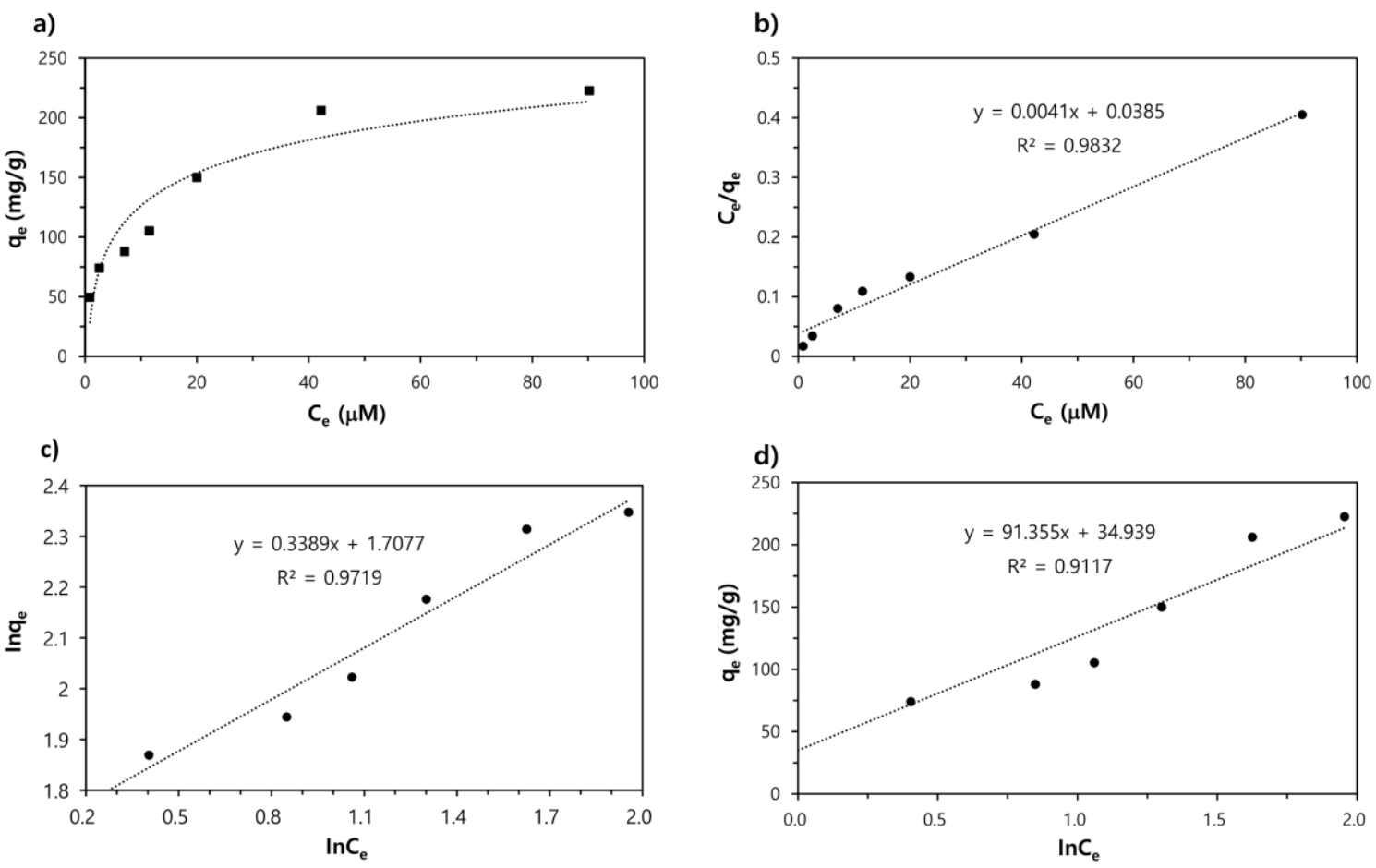

Figure 4. (a) Adsorption isotherm of Evans Blue to Fe-DC at $\mathrm{pH}$ 7. Isotherm plots and fits of the (b) Langmuir, (c) Freundlich, and (d) Temkin models. Equations used for fitting the data are listed in Section 2.4.

Table 1. Obtained isotherm model parameters for the adsorption of Evans Blue.

\begin{tabular}{|c|c|c|c|c|c|c|c|c|}
\hline $\begin{array}{l}\text { Isotherm } \\
\text { Equation }\end{array}$ & Equation & $\underset{(\mathrm{mg} / \mathrm{g})}{q_{\mathrm{m}}}$ & $\underset{(\mathrm{L} / \mathrm{mg})}{\mathrm{K}_{\mathrm{L}}}$ & $\begin{array}{c}K_{F}\left(L^{-1 / n}\right. \\
\left.m^{1-1 / n}\right)\end{array}$ & $n$ & $\begin{array}{c}A_{t} \\
(\mathrm{~L} / \mathrm{g})\end{array}$ & $\begin{array}{c}\text { B } \\
(\mathrm{J} / \mathrm{mol})\end{array}$ & $R^{2}$ \\
\hline Langmuir model & (1) & 243.902 & 0.106 & - & - & - & - & 0.9832 \\
\hline Freundlich model & (2) & - & - & 5.516 & 2.95 & - & - & 0.9719 \\
\hline Temkin model & (3) & - & - & - & - & 1.465 & 91.355 & 0.9117 \\
\hline
\end{tabular}

\subsection{The Removal of Five Anionic Dyes Using Fe-DC}

To apply the present method to the purification of other anionic molecules, we prepared four additional aqueous dye solutions that display different colors. Table 2 shows the structures and their physical characters of dyes including charges (i.e., number of sulfate groups), and maximum UV-vis absorption wavelengths $\left(\lambda_{\max }\right)$. To investigate removal efficiencies, dye solutions with different initial concentrations $(2.5,5.0$, and $15 \mu \mathrm{M})$ were passed through the Fe-DC. The removal efficiency (\%) obtained for the dyes (Figure 5a) can be calculated using Equation (4). At low concentration, most of the dye molecules were efficiently captured by the Fe-DC. With increasing initial dye concentration, 
the removal efficiencies for anionic dyes gradually decrease. This trend can be explained by considering that dyes at lower initial concentration are more likely to be immobilized while leaving more vacant sites on the chitosan- $\mathrm{Fe}_{3} \mathrm{O}_{4}$ nanoparticle adsorbent. On the other hand, as initial dye concentration increases, the occupied sites of the adsorbent make it more difficult to adsorb additional anionic dye molecules.

Table 2. Chemical structures and selected properties of anionic dyes.

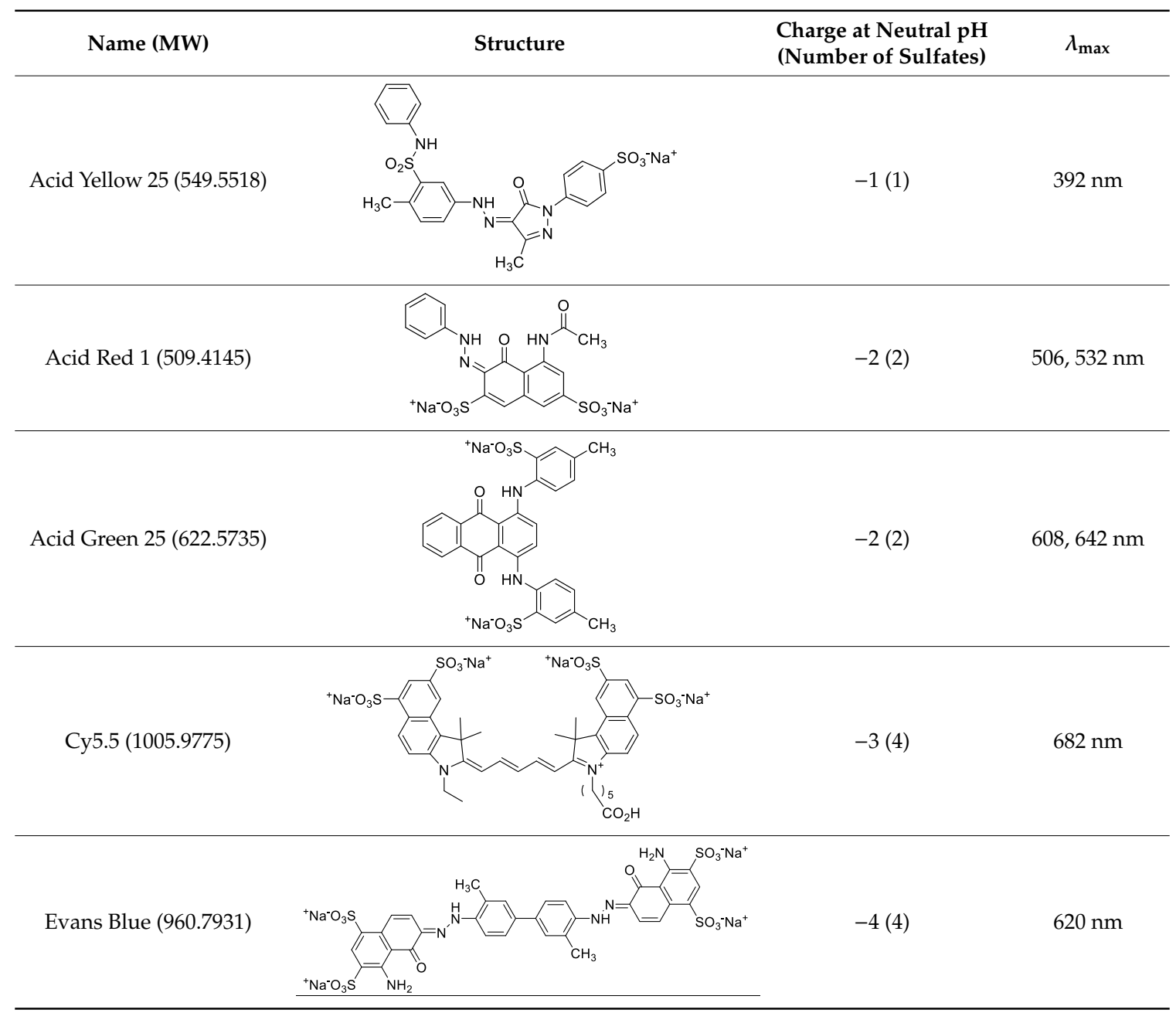

The removal of dye molecules by Fe-DC can also be visualized by photographic images of the solutions. As shown in Figure 5b,c, the intensity of the eluate color (after purification) is significantly less compared to the corresponding solution before purification (15 $\mu \mathrm{M}$ initial concentration). Interestingly, better results are obtained with more negatively charged dyes. For example, both EB and Cy5.5 contain four negatively charged sulfate groups, exhibiting better removal efficiencies compared to the other dyes containing only one or two sulfate groups. Previous studies demonstrate that the electrostatic interaction is the dominant mechanism for adsorption of charged organic dyes on the surface of metal oxide nanomaterials [29]. To stabilize the anionic charge on the dyes, interactions between these negatively charged dyes and the chitosan- $\mathrm{Fe}_{3} \mathrm{O}_{4}$ surface facilitate the adsorption process. More importantly, the sulfate group is known to possess a sufficient affinity for use as an anchoring group on the $\mathrm{Fe}_{3} \mathrm{O}_{4}$ nanoparticles [30-32]. Therefore, the sulfate anion(s) of the dye can form surface complexes with the adsorbents, leading to better removal capability with the Fe-DC. 
a)

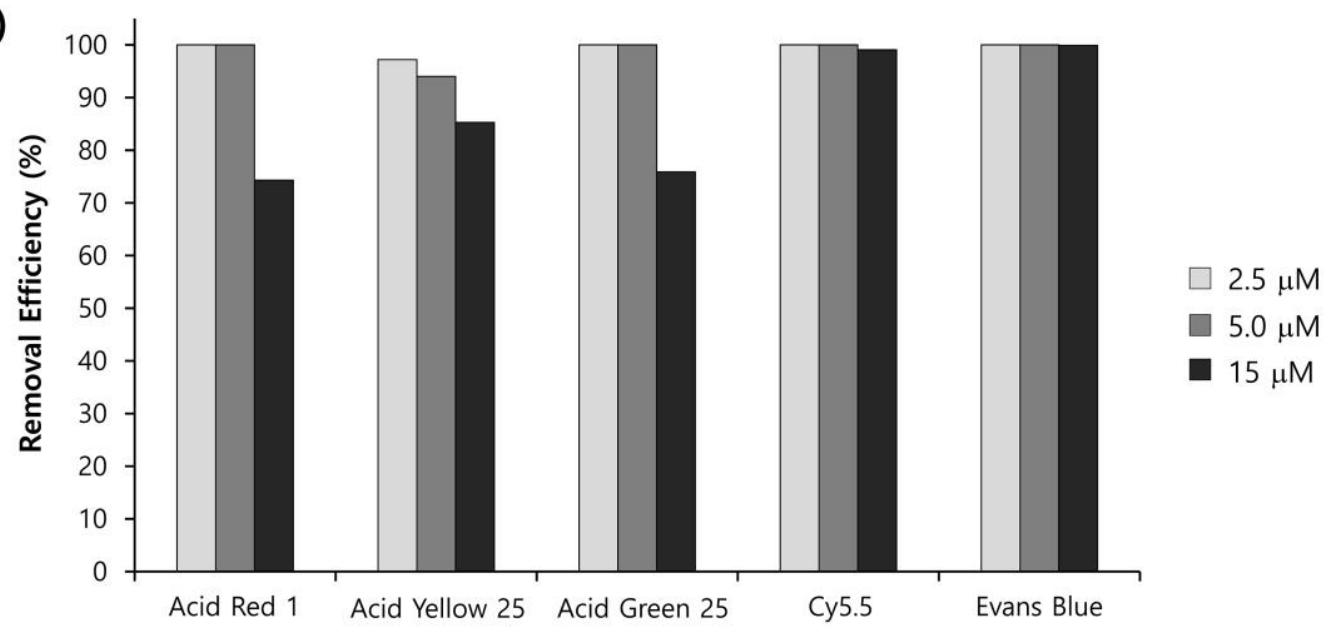

b)

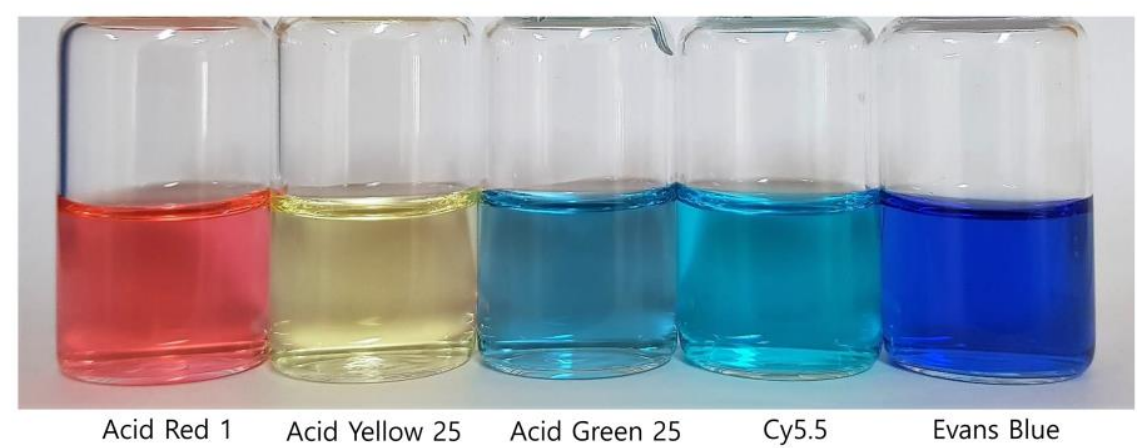

c)

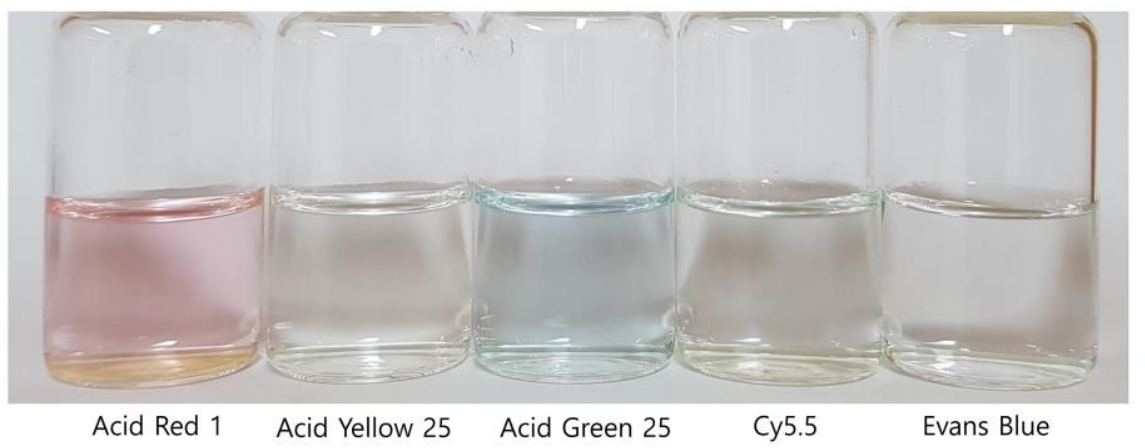

Figure 5. (a) Removal efficiencies of anionic dyes using Fe-DC (2.5, 5.0, and $15.0 \mu \mathrm{M}$ initial concentration) at $\mathrm{pH}$ 7. Photographic images (b) before and (c) after purification of anionic dyes $(15.0 \mu \mathrm{M}$ initial concentration).

Many reports on the adsorption of anionic dyes in aqueous media using various adsorbents are successfully applied in batch processing for removal of dyes [19-22,33-39]. However, these processes frequently require an additional process to separate the solid adsorbents from the water after the purification procedure is finished. Compared to these previous reports, the continuous flow system demonstrated in the present study is simpler and more efficient for removal of anionic dye contaminants in water. Fe-DC can be easily prepared in large quantities and in a short time. Notably, with a single elution of dye solution through the Fe-DC, anionic dyes can efficiently be captured by incorporated chitosan- $\mathrm{Fe}_{3} \mathrm{O}_{4}$ nanoparticle adsorbents, and the observed $q_{\max }$ values are superior to those obtained in previous studies (Table S1).

Anionic exchange resins also possess adsorption capabilities for the removal of anionic dyes [40,41]. For the corresponding comparison experiments, different amounts of Amberlite ${ }^{\circledR}-410$ and Amberlite ${ }^{\circledR}$ 900, which feature quaternary ammonium groups on the microbead surface, were incorporated in 
the same desalting column (Figure S7). Continuous flow experiments for EB removal in an aqueous solution demonstrated that much larger amount of resins (100 mg of Amberlite $\left.{ }^{\circledR}-410\right)$ were necessary to achieve a high removal efficiency of $\sim 98 \%$ (Figure S8). On the other hand, Fe-DC contained only $2.5 \mathrm{mg}$ of chitosan- $\mathrm{Fe}_{3} \mathrm{O}_{4}$ nanoparticles, and the corresponding column exhibited a better removal efficiency. This result shows that compared to large-particle-size adsorbents, nanomaterial-based ones can exhibit better adsorption performance in water. Overall, the above advantages strongly demonstrate that affinity chromatography using Fe-DC is a potentially useful method for efficient anionic dye removal.

\section{Conclusions}

In this work, we successfully developed a new purification method to remove anionic dyes from aqueous solutions. The combination of two materials, chitosan-coated $\mathrm{Fe}_{3} \mathrm{O}_{4}$ nanoparticles and a commercially available cross-linked dextran gel, afforded a useful affinity column, Fe-DC. The three-dimensional structure of immobilized adsorbents was characterized by the SEM-EDX analysis. Fe-DC conveniently separates dye molecules using simple elution of contaminant solutions. Moreover, this procedure does not involve magnetic separation of adsorbents. Factors such as initial dye concentration, initial solution $\mathrm{pH}$, and molecular charge have a noticeable impact on the adsorption capacity and removal efficiency. The experimental results of the Fe-DC adsorption isotherms fit well to the Langmuir model. We have demonstrated adsorption of five anionic dyes using a continuous flow system, with the more negatively charged dyes exhibiting larger maximum theoretical adsorption capacity. The purification capability of the current method compares favorably with most previous results using batch processing. Our results suggest that Fe-DC is a promising adsorbent system worth investigating for large-scale removal of anionic dyes.

Supplementary Materials: The following materials are available online at http:/www.mdpi.com/2079-4991/9/ 8/1164/s1, Figure S1: Zeta potential of chitosan-coated $\mathrm{Fe}_{3} \mathrm{O}_{4}$ nanoparticles, Figure S2: Hydrodynamic size of chitosan-coated $\mathrm{Fe}_{3} \mathrm{O}_{4}$ nanoparticles, Figure S3: Incorporation of chitosan-coated $\mathrm{Fe}_{3} \mathrm{O}_{4}$ nanoparticles in the dextran gel column (PD-10), Figure S4: $(a, b)$ SEM images of EB-adsorbed dextran gel beads, (c) EDX analysis of EB-adsorbed dextran gels, Figure S5: Elution of EB solution to Fe-DC, before purification (left), elution of dye (middle), after purification (right), Figure S6: Effect of adsorption capacity in the presence of humic acid (HA), Figure S7: (a) Amberlite ${ }^{\circledR}-410$ resin-incorporated dextran gel column (left), Fe-DC (right), (b) After elution of EB solution $(15 \mu \mathrm{M})$ to columns, Figure S8: Comparison of removal efficiency of EB dyes using adsorbent-incorporated columns, Table S1: Comparison of $\mathrm{Fe}_{3} \mathrm{O}_{4}$-based adsorbents in terms of their anionic dye removal efficiencies.

Author Contributions: J.J. conceived and designed the experiments. S.Y.L. and H.E.S. performed the fabrication of nanocomposite materials and water purification experiments. J.E.Y. and Y.J.C. performed the analysis of nanomaterials. J.J. wrote the manuscript and all authors approved the final version of the manuscript.

Funding: This research was funded by the National Research Foundation of Korea (Grant number: 2019R1F1A1061596).

Conflicts of Interest: The authors declare no conflict of interest.

\section{References}

1. Lefebvre, O.; Moletta, R. Treatment of organic pollution in industrial saline wastewater: A literature review. Water Res. 2006, 40, 3671-3682. [CrossRef] [PubMed]

2. Zhang, Y.; Wu, B.; Xu, H.; Liu, H.; Wang, M.; He, Y.; Pan, B. Nanomaterials-enabled water and wastewater treatment. NanoImpact 2016, 3-4, 22-39. [CrossRef]

3. Cai, Z.; Sun, Y.; Liu, W.; Pan, F.; Sun, P.; Fu, J. An overview of nanomaterials applied for removing dyes from wastewater. Environ. Sci. Pollut. Res. 2017, 24, 15882-15904. [CrossRef] [PubMed]

4. Ahmad, A.; Mohd-Setapar, S.H.; Chuong, C.S.; Khatoon, A.; Wani, W.A.; Kumar, R.; Rafatullah, M. Recent advances in new generation dye removal technologies: Novel search for approaches to reprocess wastewater. RSC Adv. 2015, 5, 30801-30818. [CrossRef]

5. Buvaneswari, N.; Kannan, C. Plant toxic and non-toxic nature of organic dyes through adsorption mechanism on cellulose surface. J. Hazard. Mater. 2011, 189, 294-300. [CrossRef] [PubMed] 
6. Carneiro, P.A.; Umbuzeiro, G.A.; Oliveira, D.P.; Zanoni, M.V.B. Assessment of water contamination caused by a mutagenic textile effluent/dyehouse effluent bearing disperse dyes. J. Hazard. Mater. 2010, 174, 694-699. [CrossRef]

7. Baan, R.; Straif, K.; Grosse, Y.; Secretan, B.; El Ghissassi, F.; Bouvard, V.; Benbrahim-Tallaa, L.; Cogliano, V. Carcinogenicity of some aromatic amines, organic dyes, and related exposures. Lancet Oncol. 2008, 9, 322-323. [CrossRef]

8. Patra, A.S.; Ghorai, S.; Ghosh, S.; Mandal, B.; Pal, S. Selective removal of toxic anionic dyes using a novel nanocomposite derived from cationically modified guar gum and silica nanoparticles. J. Hazard. Mater. 2016, 301, 127-136. [CrossRef]

9. Banerjee, S.; Chattopadhyaya, M.C. Adsorption characteristics for the removal of a toxic dye, tartrazine from aqueous solutions by a low cost agricultural by-product. Arab. J. Chem. 2017, 10, S1629-S1638. [CrossRef]

10. Chen, B.; Liu, Y.; Chen, S.; Zhao, X.; Yue, W.; Pan, X. Nitrogen-rich core/shell magnetic nanostructures for selective adsorption and separation of anionic dyes from aqueous solution. Environ. Sci. Nano 2016, 3, 670-681. [CrossRef]

11. Chen, J.; Chen, H. Removal of anionic dyes from an aqueous solution by a magnetic cationic adsorbent modified with DMDAAC. New J. Chem. 2018, 42, 7262-7271. [CrossRef]

12. Wang, Y.; Zhao, L.; Peng, H.; Wu, J.; Liu, Z.; Guo, X. Removal of anionic dyes from aqueous solutions by cellulose-based adsorbents: Equilibrium, kinetics, and thermodynamics. J. Chem. Eng. Data 2016, 61, 3266-3276. [CrossRef]

13. Lee, L.-W.; Pao, S.-Y.; Pathak, A.; Kang, D.-Y.; Lu, K.-L. Membrane adsorber containing a new Sm(III)- organic framework for dye removal. Environ. Sci. Nano 2019, 6, 1067-1076. [CrossRef]

14. Herrero, M.; Stuckey, D.C. Bioaugmentation and its application in wastewater treatment: A review. Chemosphere 2015, 140, 119-128. [CrossRef] [PubMed]

15. Merzouk, B.; Gourich, B.; Madani, K.; Vial, C.; Sekki, A. Removal of a disperse red dye from synthetic wastewater by chemical coagulation and continuous electrocoagulation. A comparative study. Desalination 2011, 272, 246-253. [CrossRef]

16. Cao, J.; Luo, B.; Lin, H.; Xu, B.; Chen, S. Visible light photocatalytic activity enhancement and mechanism of $\mathrm{AgBr} / \mathrm{Ag}_{3} \mathrm{PO}_{4}$ hybrids for degradation of methyl orange. J. Hazard. Mater. 2012, 217-218, 107-115. [CrossRef] [PubMed]

17. Parsa, J.B.; Golmirzaei, M.; Abbasi, M. Degradation of azo dye C.I. Acid Red 18 in aqueous solution by ozone-electrolysis process. J. Ind. Eng. Chem. 2014, 20, 689-694. [CrossRef]

18. Mirzaei, A.; Chen, Z.; Haghighat, F.; Yerushalmi, L. Enhanced adsorption of anionic dyes by surface fluorination of zinc oxide: A straightforward method for numerical solving of the ideal adsorbed solution theory (IAST). Chem. Eng. J. 2017, 330, 407-418. [CrossRef]

19. Liu, X.; Tian, J.; Li, Y.; Sun, N.; Mi, S.; Xie, Y.; Chen, Z. Enhanced dyes adsorption from wastewater via $\mathrm{Fe}_{3} \mathrm{O}_{4}$ nanoparticles functionalized activated carbon. J. Hazard. Mater. 2019, 373, 397-407. [CrossRef]

20. Li, X.; He, Y.; Sui, H.; He, L. One-step fabrication of dual responsive lignin coated $\mathrm{Fe}_{3} \mathrm{O}_{4}$ nanoparticles for efficient removal of cationic and anionic dyes. Nanomaterials 2018, 8, 162. [CrossRef]

21. Khosravi, M.; Azizian, S. Adsorption of anionic dyes from aqueous solution by iron oxide nanospheres. J. Ind. Eng. Chem. 2014, 20, 2561-2567. [CrossRef]

22. Yao, Y.; Miao, S.; Liu, S.; Ma, L.P.; Sun, H.; Wang, S. Synthesis, characterization, and adsorption properties of magnetic $\mathrm{Fe}_{3} \mathrm{O}_{4} @$ graphene nanocomposite. Chem. Eng. J. 2012, 184, 326-332. [CrossRef]

23. Mushtaq, S.; Yun, S.-J.; Yang, J.E.; Jeong, S.-W.; Shim, H.E.; Choi, M.H.; Park, S.H.; Choi, Y.J.; Jeon, J. Efficient and selective removal of radioactive iodine anions using engineered nanocomposite membranes. Environ. Sci. Nano 2017, 4, 2157-2163. [CrossRef]

24. Choi, M.H.; Shim, H.-E.; Yun, S.-J.; Park, S.-H.; Choi, D.S.; Jang, B.-S.; Choi, Y.J.; Jeon, J. Gold-nanoparticleimmobilized desalting columns for highly efficient and specific removal of radioactive iodine in aqueous media. ACS Appl. Mater. Interfaces 2016, 8, 29227-29231. [CrossRef]

25. Shim, H.E.; Mushtaq, S.; Jeon, J. An efficient method for selective desalination of radioactive iodine anions by using gold nanoparticles-embedded membrane filter. J. Vis. Exp. 2018, 137, e58105. [CrossRef]

26. Shim, H.E.; Yang, J.E.; Jeong, S.-W.; Lee, C.H.; Song, L.; Mushtaq, S.; Choi, D.S.; Choi, Y.J.; Jeon, J. Silver nanomaterial-immobilized desalination systems for efficient removal of radioactive iodine species in water. Nanomaterials 2018, 8, 660. [CrossRef] 
27. Xu, B.; Zheng, H.; Zhou, H.; Wang, Y.; Luo, K.; Zhao, C.; Peng, Y.; Zheng, X. Adsorptive removal of anionic dyes by chitosan-based magnetic microspheres with pH-responsive properties. J. Mol. Liq. 2018, 256, 424-432. [CrossRef]

28. Ayawei, N.; Ebelegi, A.N.; Wankasi, D. Modelling and interpretation of adsorption isotherms. J. Chem. 2017, 3039817. [CrossRef]

29. Saha, B.; Das, S.; Saikia, J.; Das, G. Preferential and enhanced adsorption of different dyes on iron oxide nanoparticles: A comparative study. J. Phys. Chem. C 2011, 115, 8024-8033. [CrossRef]

30. Walter, A.; Garofalo, A.; Parat, A.; Martinez, H.; Felder-Flesch, D.; Begin-Colin, S. Functionalization strategies and dendronization of iron oxide nanoparticles. Nanotechnol. Rev. 2015, 4, 581-593. [CrossRef]

31. Afkhami, A.; Saber-Tehrani, M.; Bagheri, H. Modified maghemite nanoparticles as an efficient adsorbent for removing some cationic dyes from aqueous solution. Desalination 2010, 263, 240-248. [CrossRef]

32. Portet, D.; Denizot, B.; Rump, E.; Lejeune, J.-J.; Jallet, P. Nonpolymeric coatings of iron oxide colloids for biological use as magnetic resonance imaging contrast agents. J. Colloid Interface Sci. 2001, 238, 37-42. [CrossRef]

33. Hlongwane, G.N.; Sekoai, P.T.; Meyyappan, M.; Moothi, K. Simultaneous removal of pollutants from water using nanoparticles: A shift from single pollutant control to multiple pollutant control. Sci. Total Environ. 2019, 656, 808-833. [CrossRef]

34. Vergis, B.R.; Kottam, N.; Krishna, R.H.; Nagabhushana, B.M. Removal of Evans Blue dye from aqueous solution using magnetic spinel $\mathrm{ZnFe}_{2} \mathrm{O}_{4}$ nanomaterial: Adsorption isotherms and kinetics. Nano-Struct. Nano-Objects 2019, 18, 100290. [CrossRef]

35. Scalese, S.; Nicotera, I.; D’Angelo, D.; Filice, S.; Libertino, S.; Simari, C.; Dimos, K.; Privitera, V. Cationic and anionic azo-dye removal from water by sulfonated graphene oxide nanosheets in Nafion membranes. New J. Chem. 2016, 40, 3654-3663. [CrossRef]

36. Rajabi, H.R.; Arjmand, H.; Hoseini, S.J.; Nasrabadi, H. Surface modified magnetic nanoparticles as efficient and green sorbents: Synthesis, characterization, and application for the removal of anionic dye. J. Magn. Magn. Mater. 2015, 294, 7-13. [CrossRef]

37. Sivashankar, R.; Sathya, A.B.; Vasantharaj, K.; Sivasubramanian, V. Magnetic composite an environmental super adsorbent for dye sequestration-A review. Environ. Nanotechnol. Monit. 2014, 1-2, 36-49. [CrossRef]

38. Qu, X.; Alvarez, P.J.J.; Li, Q. Applications of nanotechnology in water and wastewater treatment. Water Res. 2013, 47, 3931-3946. [CrossRef]

39. Liu, R.; Shen, X.; Yang, X.; Wang, Q.; Yang, F. Adsorption characteristics of methyl blue onto magnetic $\mathrm{Ni}_{0.5} \mathrm{Zn}_{0.5} \mathrm{Fe}_{2} \mathrm{O}_{4}$ nanoparticles prepared by the rapid combustion process. J. Nanopart. Res. 2013, 15, 1679. [CrossRef]

40. Khan, M.I.; Akhtar, S.; Zafar, S.; Shaheen, A.; Khan, M.A.; Luque, R.; Rehman, A.U. Removal of Congo Red from aqueous solution by anion exchange membrane (EBTAC): Adsorption kinetics and thermodynamics. Materials 2015, 8, 4147-4161. [CrossRef]

41. Wawrzkiewicz, M.; Hubicki, Z. Anion exchange resins as effective sorbents for removal of acid, reactive, and direct dyes from textile wastewaters. In Ion Exchange—Studies and Applications; Kilislioglu, A., Ed.; IntechOpen: London, UK, 2015. [CrossRef]

(C) 2019 by the authors. Licensee MDPI, Basel, Switzerland. This article is an open access article distributed under the terms and conditions of the Creative Commons Attribution (CC BY) license (http://creativecommons.org/licenses/by/4.0/). 